\title{
¿COEDUCACIÓN? MEJOR, MODELOS DIFERENCIADOS
}

Salvador Peiró I Gregori

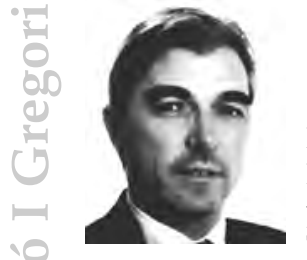

Ha desempeñado labores de docencia en las universidades españolas de Valencia y Granada, actualmente es profesor Titular en la de Alicante. Es visitante de la de Arequipa (Perú) y ha impartido cátedra en las de Austral (Argentina), Lodz (Polonia), Estrasburgo (Francia), Messina, Palermo (Italia), Querétaro (México) y otras. Ha publicado alrededor de cuarenta libros y más de cien artículos; otras tantas ponencias en congresos españoles e internacionales. Se ha especializado en teoría e historia de la educación; específicamente investiga los temas de indisciplina, violencia y valores en educación.

Correo electrónico: [salvador.peiro@ua.es].

\section{RESUMEN}

El autor sistematiza la información habida hasta la fecha en que finalizó el trabajo -2005- sobre los modelos de educación mixta y diferenciada. Después de plantear analíticamente los conceptos básicos, ofrece las tesis de la coeducación. Los defensores de este modelo no aducían aspectos sobre el rendimiento académico, que el autor sí incluye. También estudia los modelos desde las dimensiones de la indisciplinaviolencia escolares, resultados en los estudiantes, y sus concomitancias con respecto a la discriminación ocasionada por la mezcla de chicos y muchachas, consideraciones antropológicas y análisis experimentales en las aulas. El resultado es un balance a favor de la educación separada en personas de sexos diferentes. El trabajo finaliza con unas conclusiones y referencias bibliográficas. 
Palabras clave: coeducación; enseñanza mixta; sexo y violencia educacional; rendimiento académico; sexualización de las aulas.

\section{ABSTRACT}

The author systematizes the information, there been so far in that it finished the work: 2005, on the models of mixed and differentiated education. After outlining the basic concepts analytically, he offers the theses of the coeducational system authors. This model's defenders didn't adduce aspects on the academic yield that the author included. He also studies the models from the dimensions of the indiscipline-violence in schools, results in the scholars and their concomitances with regard to the discrimination caused by the mixture of boys and girls, anthropological considerations and experimental analysis in the classrooms. The result is a balance in favour of the separate education people of different sexes. The work concludes in some conclusions and bibliographical references.

Key words: coeducation; sexual combinate education; violence in education and sexual agrupations; school performance; sexual organization.

\section{INTRODUCCIÓN}

En España, el Ministerio de Educación y Ciencia (MEC) cree que la mejora de la calidad educativa es «indisociable» de la equidad referida a la prevención de desigualdades por sexo y a la escolarización corresponsable en todos los centros mantenidos con fondos públicos con los «mismos criterios de admisión» de alumnos. En respuesta escrita, fechada el 15 de noviembre de 2004, a una pregunta del diputado Francisco Rodríguez (BNG), el Gobierno reitera que el MEC está «a favor de la coeducación» en los centros de enseñanza. El Ejecutivo argumenta que la enseñanza mixta es «un medio necesario» para la formación en la convivencia en igualdad entre varones y mujeres. La administración educacional manifiesta que proporcionar una educación de calidad no consiste sólo en adquirir más conocimientos, sino también en educar en hábitos de convivencia y de respeto mutuo ${ }^{89}$. 
Este modelo ya se consideró en la década de los sesenta ${ }^{90}$ y lo estudié como monográfico de doctorado en 1976. Como quiera que este tema vuelve a considerarse públicamente ${ }^{91}$, sobre todo en aquellos Estados que tienen gestión socialdemócrata o la tuvieron en las fechas de mayor debate en España; considerando que hay nexos entre indisciplinas y violencias con la imposición del modelo coeducativo, he compuesto este trabajo con el fin de sintetizar lo nuevo que se ha aportado para poner al día el sentido pedagógico (educativo) de su aplicación.

Para llevarlo a cabo he recorrido el mundo virtual, acopiando las web más serias; he considerado artículos de los principales periódicos y diarios, así como sus monografías sobre educación. Mientras confeccionaba este trabajo, el profesor J.M. Barrio editó un libro que recoge el resultado de investigaciones sobre la materia ${ }^{92}$. De éste he tomado algunas referencias que se han intrapolado dentro de los apartados que tenía ya redactados. Espero que quede sucintamente actualizado.

\section{DEFINICIÓN DE VARIABLES EN EL TIEMPO Y EN LA ACTUALIDAD}

En primer lugar distingamos los términos que emplearemos en nuestro discurso. Dentro de la red nomológica de educación, como una de las concreciones organizativas en función del género, hay que distinguir si las clases se dan únicamente para un sexo o si se mezclan. En este sentido enseñanza mixta se pretendía definir como una vía de sólo instruir conjuntamente a ellos y ellas, sin pretender uniformar la personalidad de los chicos y chicas (se está constatando que esto no es así). La coeducación pretende que estudiantes de ambos sexos se eduquen en común y bajo un mismo modelo de persona; se trata así de desdibujar o suprimir las diferencias y valores que distinguen a varón de mujer. La educación diferenciada de los sexos busca que cada cual se distinga en sí mismo, profundizando en lo que es por el propio sexo, a la vez que estructure la subjetividad en lo común de las personas — varones y mujeres-. En la actualidad, los tres

${ }_{90} \mathrm{H}$. Loduchowky, La coeducación de los adolescentes y el problema de los teenagers.

${ }^{91}$ D.K. Hollinger y R. Adamson, Single-sex schooling: proponents speak.

${ }_{92}$ J.M. Barrio Maestre, Educación diferenciada, una opción razonable. 
enfoques se reducen a dos modelos: educación diferenciada de los sexos y coeducación, puesto que el de enseñanza mixta suele concebirse por sus partidarios como una vía para efectuar la coeducación.

La motivación por la coeducación era más bien filosófica: se trataba de defender a la mujer. El primer atisbo de preocupación por la educación de la mujer lo encontramos a fines del siglo XVIII, en el período de la Ilustración, cuando los pensadores de esa época consideraron que la ignorancia femenina era un freno a la evolución y transformación de la sociedad. Hasta entonces predominaba la idea de que la mujer se dedicara a las tareas domésticas en el hogar. Estas premisas estructuraron el modelo de educación separada tradicionalista. En Europa la primera institución coeducativa se fundó en Escocia, en el siglo XVII, extendiéndose progresivamente a muchos países europeos. En el continente americano la idea de una educación mixta surgió en el siglo XVIII, en Estados Unidos, en el marco de la industrialización creciente, en virtud de una concepción optimista, racionalista y liberal de la naturaleza humana. A partir de este hecho, la coeducación ha ido en aumento y actualmente en toda América existen muchos más centros mixtos que separados, esto quizá sea porque los alumnos y sus padres muestran sus preferencias hacia este tipo de educación.

En el Congreso de Pedagogía de 1882, celebrado en Madrid, se debatió como tema la educación femenina y la competencia de las mujeres para enseñar. En el Segundo Congreso Pedagógico, más conocido como el Congreso Hispano-Portugués-Americano, celebrado también en Madrid, en 1892, se reconoce el derecho de la mujer a la educación y se consideran como estudios más apropiados a la condición femenina la docencia, la farmacia y los servicios sanitarios, teniendo en cuenta las virtudes características de la mujer: generosidad, delicadeza, comprensión..., cualidades fundamentales para cimentar el nuevo orden social ${ }^{93}$.

El modelo de educación diferenciada de varones y mujeres ha sido el llevado a cabo por las instituciones de inspiración católica. La encíclica de Pío XI, Divini illius magistri aconseja:

${ }^{93}$ Marga Monforte, El tiempo. 
[...] igualmente erróneo y pernicioso a la educación cristiana es el método llamado coeducación, el cual se funda en un naturalismo negador del pecado original y [...] en una confusión de ideas que cambia la legítima convivencia humana por promiscuidad e igualdad niveladora.

En 1957, se la aplica como mal menor para ciertas localidades. El Concilio Vaticano II continuó asumiendo la diferenciación por el fin educativo, el carácter y sexo de educandos y educadores.

La mezcla de alumnos y alumnas se inicia y desarrolla en los Estados Unidos. La corriente liberal norteamericana, con un talante anticatólico iniciado en las primeras décadas del siglo $\mathrm{XX}$, pero acentuado desde los años sesenta principalmente, predicaba la educación combinada de ambos sexos. Con la revolución soviética de 1917 se extiende por Rusia y más tarde la suprimen (1943); después de la II Guerra Mundial, vuelve a implantarse a lo largo de la antigua URSS (1954).

Cuando en los años sesenta se inició el debate sobre la coeducación, primero se exigía la coeducación por el retraso de las mujeres en sus derechos reales dentro de la sociedad y consecuentemente en la enseñanza. Después de la implantación de las escuelas mixtas, ahora existen feministas que reclaman educación separada por la discriminación que sufren las chicas en los colegios mixtos. Hoy la preocupación es la discriminación de los chicos en los centros docentes mixtos, porque las chicas han superado en los resultados académicos a los muchachos. La generalización del modelo mixto se implanta y generaliza en España con la Ley 14/1970, que promulgara el general Franco.

\section{RAZONES O HIPÓTESIS DE LOS PARTIDARIOS DE LA COEDUCACIÓN}

El discurso pedagógico no se establece esporádicamente. Cada teoría (optimismo pedagógico, indiferenciación entre varones y mujeres, etcétera) y los modelos (coeducación, comprensividad...) que la desarrollan, suelen explicarse mediante una serie de tesis y principios. Éstos, a su vez, tratan de justificarse trascendiendo la racionalidad explicativa. El sistema mixto combina las razones causales con las del mundo de las ideas y valores. 
En cuanto a los principios y valores, que entran en la racionalidad justificativa, no voy a plantearlos aquí, pero sí anotaré los que defienden los defensores de la combinación de varones y mujeres en las aulas. Pero no deseo mencionar una controversia fundamental de tipo teórico. La alemana $\mathrm{Ch}$. Meves declara que nuestras ciencias humanas han sido contaminadas con suposiciones sobre la igualdad, hipótesis que no han sido nunca demostradas. Globalmente considerado el asunto, la idea principal sería que las diferencias entre varones y mujeres se deben al desigual trato social, que nos ha configurado como consecuencia de las pautas culturales reiteradamente asumidas y enseñadas. Y así se nos ha habituado, adquiriendo tales caracteres como costumbres. La prescripción para acabar con la supuesta falta de equidad consistiría en mezclar a los alumnos y alumnas dentro de una misma cacerola — señala Meves- para producir una igualdad de los sujetos de cualquier sexo ${ }^{94}$. Los partidarios de la coeducación se respaldan en las siguientes ideas ${ }^{95}$ :

a) Hay que organizar las enseñanzas de manera similar a como se desenvuelven las personas en su ambiente familiar (Oestreich, 1922).

b) La mezcla de sexos proporciona una convivencia más armoniosa, preparando para la vida real —equiparación democrática entre varón y mujer-, que no separa a ellos de ellas, a semejanza de la familia en donde la convivencia es muy intensa en todas las dimensiones subjetivas. Además, la escuela, ¿no debe preparar para la sociedad?

c) Mezclarles suprime la curiosidad unilateral, al equilibrar las tensiones entre los sujetos de ambos sexos. Esto acarrea la madurez afectiva, porque produce un mayor conocimiento mutuo; así que éticamente la coeducación fomenta la disminución de aberraciones sexuales, por lo que la moralidad se eleva ${ }^{96}$.

d) Las clases mixtas producen un ambiente convivencial positivo, mejor que cuando son sólo para chicos.

${ }_{94}$ Estos posicionamientos no son tan nuevos. Recordemos la obra de Simone de Beauvoir (El segundo sexo, 1949) y la contrarréplica de Hellen Fisher (El primer sexo, 2003). En medio, Rosa Montero reporta para El País (1993) un artículo de opinión que señala como progresista la educación separada de chicos y chicas.

${ }_{95}$ I. von Martial, Coeducación y educación separada, Adamas Verlag, colección Die gelbe Eihe. Se encuentra traducido por J.M. Barrio, Educación diferenciada, una opción razonable, p. 21 y ss.

${ }^{96}$ García-Hoz la menciona, sin estar concorde. Cfr. Servicio de documentación Montealegre. 
e) El paulatino desarrollo de la singularidad específica de cada género tiene lugar en el contraste de ambos géneros. Su coexistencia ocasionará rasgos femeninos en ellos y masculinos en ellas (Geheeb, 1931; Oestreich, 1922). Así, se neutralizarían las tensiones eróticas, dando paso a la camaradería (Erbe, 1957, 1970).

f) Existe equidad ante la discriminación social de la mujer, que da pie a hablar de profesiones femeninas y masculinas. La discriminación se palpa en la poca presencia de la mujer en política (Zinneker, 1972; Grätz, 1974, etcétera). La coeducación garantizaría la igualdad de oportunidades laborales (Knab, 1970).

g) El sistema mixto equipararía los roles, de modo que serían inidentificables y el sexo sería secundario. Esto llevaría a unificar el currículo y la docencia en todas las materias, incluso enseñanzas domésticas, salud familiar, etcétera (Enquete-Kommission, 1977).

h) Ante la decreciente natalidad, la concentración mixta ahorra la duplicidad de centros y la costosa doble inversión. Es más barata, pues exige menos edificios, instalaciones, recursos humanos y aulas. Pero esto sólo es válido para zonas eminentemente rurales, con una población escolar de 20 ó 30 estudiantes, que pondría la eficiencia en un docente y un aula. La mezcla implica unas ventajas económicas, administrativas, lo que se traduciría en un ahorro ante la subida de las inversiones en educación, provisión de suministros, etcétera.

i) Las familias tendrían más ventajas, pues disfrutarían de más facilidades para organizar sus desplazamientos, localización de centros...

Lo primero que llama la atención es la ausencia de cualquier tesis relativa al rendimiento académico. No obstante, sin sacarla de los autores que defienden la enseñanza mixta, deseo manifestar que es un indicador clave y fundamental para conocer la bondad de los modelos de educación. Valga, pues, este espacio para subrayarla y ofrecer el interrogante al respecto.

Con el fin de valorar la realidad de estos principios, podemos sintetizar la lista, integrando diversos postulados en cuatro parámetros del sistema escolar. Si desde la primera perspectiva miramos al mundo de los hechos, podemos considerar el objeto de la pedagogía atendiendo al producto de la educación, y ver qué modelo es más eficaz. También se puede 
contemplar desde otra mirada el resultado: los comportamientos de los escolares y referirlos a los problemas convivenciales en los establecimientos escolares. Otra perspectiva consiste en atenernos al proceso de enseñanzaaprendizaje, para saber cuál de las alternativas ofrece un clima optimizante. Y, para averiguar las razones más profundas, podemos sintetizar varios puntos mediante la consideración de la identidad sexual de los estudiantes y alumnas desde una antropología integrativa.

Ante tales premisas, no cabe otra alternativa que investigar. No se debe basar el discurso pedagógico en una mera disputa sobre justificaciones. Además de las razones, hay que aducir análisis.

\section{ANÁlISIS PEDAGÓGICO DE LAS HIPÓTESIS MEDIANTE DIVERSAS INVESTIGACIONES}

Riordan ${ }^{97}$ afirma que los investigadores están llevando a cabo un exhaustivo análisis de las publicaciones al respecto y ha identificado más de 2 mil estudios. Se realiza un primer corte del examen efectuado por él y A. Mael — de AIR - sobre escuelas de un solo sexo, controlando factores como el nivel, estatus socioeconómico, raza, idoneidad docente, gastos de los escolares y disciplina. Luego escogen seis escuelas de único sexo para llevar a cabo una observación más profunda. El estudio preliminar (aplicado a una población-muestra de más de 2 mil alumnos) parte de una nota que espera comprobaciones, y es que los investigadores tienen sus reservas respecto a los hallazgos ${ }^{98}$.

${ }^{97}$ C. Riordan, «Girls and Boys in school: together or separate?».

${ }_{98}$ Researchers are beginning with an «exhaustive» review of existing literature on the topic, Mr. Riordan said, and they have already identified more than 2,000 studies to examine. Those will include research done by Mr. Riordan and Fred A. Mael of the AIR, who is also participating in this new study. «First Cut» That review will be followed by a survey of existing public single-sex schools, looking at a wide range of factors, including grade levels, socioeconomic status of students, race, teacher credentials, per-pupil expenditures, and discipline, Mr. Riordan said. Later, the researchers will choose six single-sex schools for in-depth observations. Conclusions from the study should be available by March 2006, though some preliminary results may come out sooner, Mr. Riordan said, and they have already identified more than 2,000 studies to examine. In this preliminary, Riordan said. «I think the results will take us a long way since nothing like this has ever been done in the public sector», he said. «This will be our first cut at it». But Mr. Riordan said researchers were in a quandary. The proposed regulations, which are in the midst of a 45-day review period, would amend Title IX of the Education Amendments of 1972. Title IX prohibits sex discrimination in education programs that receive federal funds, at: http:[/ / www.edweek.org]. 
Ante los modelos coeducación y diferenciación, ¿es uno mejor que otro? ¿Qué dicen las investigaciones actuales respecto a tal aporía? Contamos con diversos trabajos, así como con un estudio que sintetiza 180 investigaciones e informes anteriores al año 2000; uno de 1977 y la mitad de los años ochenta y el resto de los noventa —el último de 1998-, e inferimos que no podemos efectuar afirmaciones tajantes, aunque contradicen ciertos deseos escritos.

III.1. Primero nos fijamos en lo más concreto: la educación como producto. Esto implica también la perspectiva profesional de los estudiantes en cuanto a su orientación al mundo del trabajo como egresados del sistema escolar. Se trata del éxito o no en los estudios; es el problema del fracaso escolar. La mayoría de los resultados de los investigadores asegura que la educación diferenciada proporciona un mejor resultado académico en ambos sexos, siendo la afirmación menos ambigua para ellas que para ellos ${ }^{99}$.

La diferenciación beneficia a las alumnas en sus aspiraciones curriculares (carreras), lo cual - esto es interesante, pues pareciera lo contrariorepercute en la organización de los estudios postsecundarios. Los datos disponibles no indican que haya una convergencia de intereses y expectativas en ambos sexos en materia de formación y salida profesional. Bajo la presión coeducativa, la elección de asignaturas específicas se ha consolidado más que en el modelo diferenciado por sexos (Stanworth, 1986). La mayoría de las chicas sigue las asignaturas biología, filológicas y artísticas; los alumnos optaron por matemáticas, física y química. Analizando y comparando diversas tablas ${ }^{100}$ se infiere que la coeducación discrimina especialmente en lo académico-laboral a las alumnas.

99 R.W. Conlon, «Teaching the boys: New research on masculinity and gender strategies for schools», Teachers College Record, p. 206-235; D. Kindlon y M. Thompson, Educando a Caín; J. Kleinfeld, «Student performance: males versus females», Public Interest, 3, 20; W. Pollack, Real Boys: Rescuing our sons from the myths of boyhood; L. Yates, «Gender equity and the boys: What sort of challenge is it?», British Journal of Sociology of Education, 18, 3.

${ }^{100}$ Siguiendo este sistema, von Martial, aparte de unas reflexiones, menciona cuadros estadísticos de los años académicos 1975-1976, 1983-1984 al 1985-1986, así como otros de 1994-1995, 1996-1997... Cfr. J.M. Barrio, op. cit., p. 33-40. 
En Alemania, la defensa de la educación diferenciada para las chicas surge ahora desde las filas feministas: «Lo que a finales de los años sesenta se celebró como una gran reforma - la enseñanza conjunta de chicos y chicas en todas las asignaturas - ha resultado ser un fallo tremendo. La idea de los reformadores, como se está viendo cada vez más claro, fue uno de los errores pedagógicos más graves de los últimos decenios» (Der Spiegel, 6-V-96). Así, la revista feminista Etruria habla siempre de la «K.O edukation» y pide una separación inmediata por sexos para «proteger a las chicas del dominio masculino». La feminista Flore Hoffmann, pedagoga de la Universidad de Kiel, reconoce que con la educación diferenciada se consigue que las chicas se interesen mucho más por «las típicas asignaturas de chicos como son informática, química o matemáticas, al estar las clases orientadas según sus necesidades». Feter Struck, de la Universidad de Hamburgo, señala que «[...] aunque las clases mixtas siempre se han presentado como un avance, la separación de chicos y chicas sería una ventaja para todos». También la línea estadounidense va en este sentido ${ }^{101}$.

Johanna Mehier asegura que en la mixta:

[...] las chicas pierden el interés por las matemáticas y ciencias, al verse superadas constantemente por los chicos. Pero eso se debe a que con la coeducación no se han tenido en cuenta las diferencias reales entre chicos y chicas. Los planes de estudio no se han adaptado, sino que se han dejado como estaban: pensados para los chicos. Las chicas van a otro ritmo, pero pueden llegar a entender y asimilar mejor que los chicos los aspectos de físicas o matemáticas [...]. Experimentos escolares en Berlín, Hamburgo, Baja Sajonia y Westfalia han demostrado que las chicas se pueden entusiasmar por las asignaturas calificadas de masculinas, tan pronto como se encuentran entre ellas y se «ven liberadas» del etiquetado: ser muñecas sin aptitudes en las asignaturas técnicas.

${ }^{101}$ Linda Chavez placed great weight on a Johns Hopkins study. Cfr. Los Angeles Times, [http: / / www.latimes.com/], 23-I-2005. All-girls schools hold great promise for eliminating the gender imbalance in math and science. A study of graduates of girls' high schools in the United States found that $13 \%$ went on to major in hard sciences and math, compared with only $2 \%$ of girls who attended coed schools. In other words, girls who attend all-girls schools are more than six times as likely to earn degrees in the very subjects about which Summers professes concern. 
El Colegio Arapahoe High, Colorado, Estados Unidos, ofrece clases homogeneizadas por sexo para matemáticas, lectura, manualidades y natación. Los docentes esperan que ahora mejoren los resultados de los chicos, pues han caído con respecto a sus compañeras en todas las categorías. Su director, Ron Booth, lo explica afirmando que chicos y chicas son diferentes y aprenden de manera distinta, ¿por qué no intentar enseñarles enfocando sus puntos fuertes de manera diferenciada? (Associated Press, 11-X-2004). Estudios a pequeña escala efectuados por el National Charter School Clearinghouse constatan que los promedios de puntuación para ambos sexos aumentan en séptimo y octavo grado, cuando se les separan. También se menciona que las chicas se tornaban más competitivas o destacaban más en las aulas y que los chicos mejoraban su trabajo en equipo (Denver Post, 11-X-2004).

Que la coeducación genera desigualdades está bien documentado, por lo que la educación diferenciada puede aliviar problemas y un pernicioso sexismo que traspasa los centros docentes ${ }^{102}$. Con esta conclusión quedan refutadas las tesis e), f) y g). Por otra parte, al separar alumnos de alumnas sucede al contrario: las escuelas diferenciadas (single-sex) consiguen mejor la igualdad profesional ${ }^{103}$. Con la coeducación, desde la perspectiva del resultado y rendimiento escolar, no sólo los chicos sufren retraso general, sino que han de pagar clases particulares, lo cual es inequívocamente una inequidad ${ }^{104}$. También en este sentido, la sociología escolar señala que

${ }^{102}$ The GSA (Girl's Schools Association) says its study shows girls in single-sex schools are less likely to be stereotyped by avoiding or being steered away from «boys' subjects». Cynthia Hall, president of the GSA and head of St Helen and St Katharine School in Abingdon, Oxfordshire, said: «No matter how much teachers encourage girls, if there are boys around, girls get put off and think they can't do the harder subjects. Boys are ready to sound off and make the girls feel they can't do science and the girls back off». Dr Vivienne Nathanson, who heads the British Medical Association's science and ethics committee, believes that science is perceived as a male subject in co-educational schools. (Geraldine Hackett, «Education», The Sunday Times, 14-XI-2004).

${ }^{103}$ Christina Odone, «Single-sex schools get top marks», Times Online, 18-XI-2004.

${ }^{104}$ «I ragazzi sono quelli che sembrano soffrire maggiormente della situazione, infatti è soprattutto a loro che vengono diagnosticati disturbo di apprendimento e di attenzione. Espesso a farsi carico del problema devono essere le famiglie, con lezioni private, i cui costi sono all'origine di una concreta discriminazione per censo». Leonardo Tondo, La Repubblica, 28-III2004. El autor es docente de psicología en la Università di Agliari y Lecturer en la Harvard Medical School de Boston, en Italia è stato tra i primi a sottolineare i rischi dell'instruzione impartita nelle classi miste. 
las chicas rinden más y mejor en asignaturas tradicionalmente masculinas, cuando están en clases de su mismo sexo ${ }^{105}$.

III.2. Indudablemente, la disminución de notas es indicio de una disfuncionalidad. Desde la consideración social, observamos alarma social ante los problemas y agresiones escolares (bulling). La hipótesis es si tales problemáticas convivenciales pueden ser derivadas por la mixtificación organizativa de los centros como uno de sus factores. En este orden de hechos, la disciplina académica resultaría también afectada por la coeducación.

Como la amistad es un valor que dificulta la práctica del bulling, encontramos que la presencia constante de muchachos en el aula, dificulta las amistades entre las alumnas ${ }^{106}$. También, continuando con esto, se constata que es mayor la capacidad de establecer y desarrollar amistades entre ellas y profesores, en los centros exclusivamente femeninos ${ }^{107}$. Por consiguiente, ciertamente, se puede afirmar que los muchachos influyen negativamente en la conducta social de las muchachas (Dale, 1969). Además, la sociometría nos confirma que los muchachos procedentes de clases mixtas tendían a adoptar más actitudes asociales y a ser más agresivos y egoístas que los procedentes de clases separadas. En vez de esto, quienes procedían de educación diferenciada se encontraban mejor predispuestos a laborar en pro de la comunidad y a comprometerse socialmente. En cuanto a ellas, en lo social no se apreciaron diferencias, pero sí en la mayor madurez de las procedentes de educación diferenciada (Joerger, 1963).

En cuanto a la función magisterial, la coeducación hace que se resienta la autoridad del docente, precisamente porque introduce y añade un nuevo ingrediente: el de las discrepancias, luchas y contradicciones entre los alumnos, a causa de las diferencias de sexo. El comportamiento de chicos y chicas también cambia con la coeducación. Las muchachas, ante la presencia de ellos, transforman el compañerismo en competitividad. Surgen las

${ }^{105}$ V.E., Lee; H. Marks y T. Byrd, «Sexism in single-sex and coeducational secondary school classroom», Sociology of Education.

${ }^{106}$ D. Eder, «The cycle of popularity: interpersonal relations among female adolescents», Sociology of education, p. 154-165.

${ }^{107}$ D.G. Smith, «Women's colleges and coed colleges: is there a difference for women», Journal of Higer Education, p. 181 y ss. 
calumnias, difamaciones y murmuraciones que debilitan la amistad que, hasta entonces, habría entre ellas. Por el contrario, los chicos hacen alarde de fuerza física renunciando a la competitividad intelectual con ellas. Hace algunos años se defendía la hipótesis de la ventaja de la coeducación en tanto que se suponía que la temprana convivencia entre chicas y chicos contribuiría a mejorar el conocimiento y la mutua aceptación. En la actualidad esas hipótesis no han podido ser verificadas. Más bien parece ser que la coeducación contribuye a que tanto las chicas como los chicos se cierren herméticamente en su propio grupo ${ }^{108}$. Por consiguiente, la tesis b) es insostenible.

En lo tocante a las acciones de los chicos, a menudo, las agresiones de abuso sexual van acompañando a las psíquicas y verbales; incluso incidiendo hacia las profesoras (Brehmar, 1988). Ellas suelen elegir estrategias no violentas para solventar discusiones y enfrentamientos, por lo que se aprecia una fuerte dominancia de los alumnos (Wieland, 1995). Con esto se demuestra la inviabilidad de la tesis c).

Investigaciones bioquímicas y fisiológicas abundan en esto, dándonos explicaciones. Dicen los expertos que los varones portan sólo un cromosoma X, además del cromosoma Y. Este es más corto y posee muy pocos genes. La gran sorpresa fue constatar que un buen paquete de genes del cromosoma $\mathrm{X}$ de la mujer no está silente. Para Laura Carrel, de la Universidad del Estado de Pensilvania, unos 200 a 300 de estos genes no apagados podrían explicar diferencias entre los varones y las mujeres, como rasgos vinculados con la agresividad, que no serían atribuibles a factores puramente hormonales ${ }^{109}$. Así, en el varón predomina la búsqueda de independencia y el aprendizaje de poder o de dominio, de ahí la mayor conflictividad potencial con el profesor ${ }^{110}$.

\footnotetext{
${ }^{108}$ Marga Monforte, El Tiempo.

${ }^{109}$ A. Lilian Duery, El Mercurio.

${ }^{110}$ M. Calvo, Todos iguales pero diferentes. El derecho a una educación diferenciada, p.273.
} 
En 1973, Whiting/Edwards estudiaron comparadamente a sujetos de siete culturas diferentes, encontrando unos rasgos agresivos verbal y físicamente como característicos de los chicos ${ }^{111}$. También menciona von Martial que los lineamientos dados por la empiria tienden a caracterizar una mayor prosocialidad en las chicas, valorándose los varones a sí mismo más dominantes que las mujeres. Prosiguiendo más hacia lo interior de la personalidad, menciona investigaciones de Guilligan (1984). Esta investigadora, en vez del juicio moral procedimental de tipo razonamiento moral (Kohlberg), especifica el carácter moral femenino como más propenso a desarrollarse mediante la asistencia social y a la responsabilidad. La tendencia hacia la pelea por los chicos está confirmada por un estudio de la Universidad de Bermont (1997) que analizó el comportamiento de niños de doce países desarrollados y no-desarrollados ${ }^{112}$.

El estudio PISA de 2001, realizado transversalmente entre los países de la OCDE, concluye que el fracaso escolar de muchos chicos, pone en peligro la cohabitación de ambos sexos en la escuela. Tal vez por esto, otros expertos nos señalan que las clases mixtas son factor de intimidación; hay una pobre autoconciencia y se pierde la confianza con terceros. Como el ambiente es competitivo, es duro aprender en ese clima de relaciones. Los procesos en grupos unisexuales son mejores ${ }^{113}$. El sociólogo francés, Michel, relacionaba esto con la situación que viven los colegios

${ }^{111}$ Barrio, J. Ma . plasma el trabajo de Von Martial, quien meciona investigaciones de Hutt, 1972; Maccoby/Jacklin, 1974 y Degenhart, 1979. Valga también esta anotación: «And you don't need to be a devout Muslim who wants her daughter to wear a veil or an evangelical Christian who wants his children to learn creationism, to opt for schooling that shields them from the precocious sexualisation that pervades every corner of society. Why should your 12-year-old daughter be surrounded by testosterone-crazed boys desperate to get off with anyone they can, when you could spare her the distraction and let her focus on getting into a top university? Why choose to enrol your son in a school where his natural inclination for languages condemns him to playground taunts?» («Single-sex schools get top marks». Times Online).

${ }_{112}$ M. Calvo, op. cit., p. 273.

${ }_{113}$ «When classes are mixed, there's kind of an intimidation factor there. No matter how good you are, you are always a little self-conscious», said Emily Jacob... «When it's just women, we tend to boost each other's confidence. We always encourage other women. It's not that competitive. Sometimes it can be hard to learn in a competitive environment». Now, gearmakers and outdoor educators are coming around. They are creating specialized learning environments without men. «Women-specific gear gives women the confidence they need to be successful». Randy Hurlow, spokesman for REI, [www.REI.com]. 
franceses, que tienen cada vez más problemas de agresiones sexuales, así como un descenso en los resultados académicos ${ }^{114}$. Consecuentemente, las reacciones ante los tropiezos en la vida académica no son «normales».

Es momento de reflexionar sobre la falacia del principio de socialización, que está confusamente formulado en las hipótesis de planteamiento. Ciertamente, como proponen los coeducacionalistas, hay que socializar. Entonces, como en la vida no-escolar, cada cual tiene su lugar y compañeros para trabajar, practicar deporte, convivir en familia, estudiar, etcétera, es decir, se trata de espacios y tiempos con gente distinta. Los adolescentes, si están siempre juntos, como afirma la experiencia, se acoplan en parejas. Entonces, si rompen... la convivencia no únicamente es áspera, sino que genera bandos partidarios de uno y otra. Si pensamos en un fenómeno indisciplinario, como es el pandillismo, encontramos aquí una de las causas. Al contrario que en la sociedad real que, ante rupturas, los del trabajo se enteran - pero sin generar ningún choque emotivo-, así mismo sucede con los demás grupos. En el caso de la vida escolar, bastantes factores del bulling y abundantes casos se explicarían por estos lineamientos factoriales. Al contrario, quienes asisten a un centro con educación diferenciada, forzosamente han de diversificar sus entretenimientos y amistades fuera de los institutos de educación secundaria. En tal sentido, las escuelas diferenciadas no serían factor de riesgo ${ }^{115}$. Por tanto, no son válidas las proposiciones incluidas en la tesis a) y b).

Para concluir, la educación diferenciada de sexos genera actitudes positivas respecto al rol sexual y favorece la autoestima (formación de la personalidad). Nos hallamos, así, frente a diversos criterios que requieren más investigación y un mayor refinamiento metodológico, en vez de tan frecuentes y ligeras afirmaciones. Congruentemente, Heide Simonis, parlamentaria del Bundestag alemán por el partido socialista (SPD) y conocida feminista, está de parte claramente de la educación diferenciada: «Es necesario deshacerse definitivamente del prejuicio: el de pensar que las

${ }^{114}$ M. Fize, Les piéges de la mixtité scolaire; y artículo en ABC de 30-III-2004. Este sociólogo es especialista en temas de familia, adolescencia y juventud. Es miembro del Centre Nationale de la Recherche Scientifique. También fue asesor técnico de la que fuese ministra de Juventud y Deporte entre 1992-2002, Marie George Buffet, del Partido Comunista Francés.

${ }^{115}$ L. Rojas Marcos, Nuestra incierta vida normal. 
escuelas femeninas producen sólo feministas enemigas de los varones, y que las chicas necesitan clases conjuntas con los chicos para no estar en desventaja en el trabajo profesional. Esto es totalmente falso, como lo es también la afirmación de que chicos y chicas aprenden a conocerse mejor gracias a clases mixtas» (Der Spiegel, 6-V-96).

En resumen, el modelo profesional resultante del enfoque curricular está definido como masculino. Por ejemplo, la exigencia de cualidades masculinas como habilidades adquiridas con el desarrollo del plan de estudios, en la capacidad de gestión, comportamiento resuelto, expresión segura (Mitterlehner-Bergk, 1991). Por consiguiente, podemos concluir que las discordancias son causadas por factores estructurales del sistema educativo, tales como son el agrupamiento mixto o coeducativo, puesto que, aunque los chicos dominan la situación, ellas aprenden más. Los varones se están convirtiendo en el sexo vulnerable por el alto grado de fracaso académico derivado de un proceso tenso y de riesgo, pues el menor rendimiento puede generar complejo de inferioridad, descenso de la autoestima, necesidad de evadirse de la realidad del aula, con el consecuente absentismo escolar y los entretenimientos que lo acompañan: consumo de alcohol y drogas ${ }^{116}$.

Por tales razones, la tesis f) y g) - la coeducación desarrolla disciplina en los chicos- es de consistencia débil y con soporte científico equívoco; por lo que es evidentemente inválida. En cambio, sí se constata que la educación diferenciada reduciría la violencia y el acoso contra las alumnas ${ }^{117}$. Corolariamente, como Fize aconseja, para los alumnos que estén insertos en procesos de indisciplinas y violencias, es importante hacer una pausa voluntaria en la coeducación, asistiendo a clases separadas.

\footnotetext{
${ }^{116}$ S. Kraemer, «The fragile male». British Medical Journal.

${ }^{117}$ Cesare Cavalleri, Avvenire, 14-VII-2004. Michael Thompson, psicologo in una scuola maschile e autore dei libri «Educare Caino: come proteggere la vita emotiva dei ragazzi», e «Parlando di ragazzi», assicura che, durante l'adolescenza, nel confrontarsi con le ragazze nella scuola secondaria i ragazzi si vedono «difettosi», e finiscono per diventare «intrattabili e risentiti». Secondo Carol Gilligan, dell’Università di New York e autrice di diversi libri sulla psicologia delle adolescenti: «Le ragazze di 11 anni hanno fiducia in se stesse, mentre a 16 anni sono confuse», sostiene la psicologia, convinta che le ragazze saranno più creative e audaci da adulte se nell'adolescenza ricevono un'educazione differenziata.
} 
También considera este sociólogo francés que debido a los diferentes intereses originados en las aulas — sobre todo en educación física y educación sexual一, puede ser útil la separación ${ }^{118}$.

$\mathrm{Si}$ analizamos el trasfondo de estas proposiciones, entendemos que estamos situándonos en los procesos educacionales. Es decir, ¿qué sucede en las relaciones humanas escolares para que se perturbe el logro de los objetivos cognoscitivos, afectivos y sociales? Por ejemplo, los chicos se quejan de que se les castiga con más frecuencia, ellos señalan que es porque hacen lo propio de ellos; las alumnas, al permanecer sentadas y atender, no «molestan»; así se establece un clima de etiquetado en contra de los varones ${ }^{119}$. Con estos datos nos situamos en otra faceta de la educación, que consideraremos procesualmente.

III.3. Analizando el proceso de enseñanza-aprendizaje llegaremos a saber la problemática de la disminución de notas y el clima anticonvivencial de los centros mixtos, sobre todo entre los varones ${ }^{120}$. Comencemos con la dominación de los espacios y el consecuente clima relacional que acarrea esto. Desde esta perspectiva, el dominio de los muchachos ante las chicas, se aprecia en la ocupación de los mejores asientos para ver la pizarra más cómodamente. En concomitancia con lo referido antes con relación a la indisciplina y la violencia escolares, esta situación en el aula refleja los estereotipos sexistas, sobre todo el machista. Pues, a la vez que acaparan lo mejor, se produce un distanciamiento físico, que se extiende hasta las zonas de recreo ${ }^{121}$.

En las interacciones dentro de las aulas, existe un dominio masculino en las clases mixtas: «Los chicos intervienen en las clases el doble que las chicas, y reciben muchas más alabanzas y castigos pues por su activismo, llaman más la atención. Las intervenciones de las chicas son interrumpidas

${ }^{118} \mathrm{M}$. Fize, Les pièges de la mixité scolaire.

${ }^{119}$ J. Wendland, «Reversing the Gender gap», Political Affairs-A Marxist Monthly. En vez de «etiquetar», dice «criminalizar».

${ }^{120}$ S. Kraemer, «The fragile male», British Medical Journal, p. 1606-1612.

${ }^{121}$ Mosconi, La mixité dans l'enseignement secondaire: un faux semblant? Otros trabajos, en 2004, desarrollan esta idea. 
y completadas por aclaraciones de los chicos. Los chicos con buenas notas son calificados por los profesores como despiertos e inteligentes, mientras que las chicas con buenas notas son consideradas como trabajadoras y ordenadas» (Der Spiegel, 6-V-96). Por lo que este modo, el etiquetado es el inicio de un proceso vicioso.

Analizando el modelo desde el contenido de las lecciones, se constata que si el docente explica de modo razonado y analítico, las niñas suelen aburrirse; si lo hace de manera ágil y explícita, ellas lo captan y los chicos no lo acaban de comprender ${ }^{122}$. Ya hemos publicado la relación que existe entre el fracaso escolar y la indisciplina con la reiterada inatención, pues también se presentan conexiones con la coeducación. Por ejemplo: Gill Pyatt, profesora jefe en la Barnwood Park High School para chicas, afirmó que los beneficios de la educación separada por sexos son sustanciales. «Nuestras chicas pueden trabajar sin distracciones» ${ }^{123}$.

Pero esta inadecuación metodológica no sucede sólo en el bachiller, también, comenzando desde la escuela primaria hasta llegar a los cursos avanzados, existen diferencias en la captación de la atención del docente. Y éste se las ha de ver con las muestras de indisciplina, que se producen en las actividades que exigen más esfuerzo e interés (EndersDragäser/Fuchs, 1993). Así mismo, ellos reclaman la atención de la maestra cuando se dedica a ellas, forzando que les atienda. Por consiguiente, en vez de explicar, no se lleva a término la docencia, sino que la función del profesor se trastrueca para volverse en un mero cuidador, controlador, etcétera ${ }^{124}$. La American Association of University Woman realizó un estudio transversal con más de 1,300 chicas, constatando que, en los centros coeducacionales, éstas reciben menos atención que los chavales en lo tocante al trabajo, dudas, estimulación, etcétera ${ }^{125}$.

${ }^{122}$ M. Calvo, op. cit., p. 274.

${ }^{123}$ Telegraph de Londres, 11-VII-2004.

${ }^{124}$ A seventh-grader from Hyde Park, said that he will probably learn more without girls. «A lot of guys are going to be paying attention instead of bothering the girls». Disruptions throwing paper airplanes, standing on chairs, flicking rubber bands. "My son sort of puts on a bravado in front of the girls, and then he's not focused on what's going on in class». Tracy Jan, The Boston Globe News, 9-IV-2005.

${ }^{125}$ AAUW, How schools shortchange girls, Washington. 
Para comprender esta aseveración, hay que saber que un noventa por ciento de docentes desconocen los procesos de aprendizaje diferencial por sexos, por lo que no aplican las medidas preventivas o correctoras correspondientes. Si las conocieran, comenzarían por separarles en algún momento del proceso de enseñanza-aprendizaje, si no en todos. Equivocadamente, los docentes suelen explicar de idéntica forma a niños que a chicas, en el mismo tiempo y esperando el mismo tipo de respuesta ${ }^{126}$. La apreciación que adultos y condiscípulos tienen sobre las cualidades y rendimientos individuales, repercuten en la valoración de la personalidad sexuada de cada estudiante, de tal modo que las relaciones de los docentes hacia los muchachos y las jóvenes viene condicionada por ello ${ }^{127}$. Los profesores se adaptan mejor en sus enseñanzas con chicos. Esto promueve mayores interacciones con los del sexo masculino; resultados de encuestas nos muestran una concentración de contactos a favor de los alumnos en una proporción de $2 / 3$ (Frasck/Wagner, 1982), y más del 80 por 100 recaía sobre los muchachos (Kaiser, 1992). Esta tesis no ha sido validada en estudios empíricos para los sistemas escolares irlandeses ni suizos (Murria, 1985).

En el sistema de la coeducación, como los muchachos suelen mostrar conductas presuntuosas frente a las chicas, se pierde mucho tiempo ${ }^{128}$. No se trata de cuestiones de inteligencia sino de la maduración con la aparición de ciertas habilidades — lingüísticas, psicomotrices, etcétera- que exigen maneras y tiempos específicos ${ }^{129}$. Así se sigue una dinámica diferente

${ }^{126}$ M. Calvo, op. cit., p. 276.

${ }^{127}$ Von Martial, en J.M. Barrio, p. 54.

${ }^{128}$ Teachers are already reporting improvement in getting classes settled in quickly. «It especially seems to be helping the boys», Gibson said. «Boys at this age spend a lot of time showing off» for girls. With single-sex classes, «a lot less time is wasted», she said. The Birmingham News, 29-X-2004.

${ }^{129}$ «È una questione di modi e di tempi, non di intelligenza: sono le abilità che maturano in modo diverso. Le ragazze hanno maggiori capacità verbali, e le sviluppano presto, mentre i loro coetanei maschi sono forzati ad apprendere cose in cui sono pronti, a scapito di altre capacità, come quelle visivo-spaziali, che in loro maturano prima. Questa forbice crea problemi che permangono per tuto il periodo scolastico, poiché è solo intorno al 18-20 anni che le differenze si compensano». Cfr. Leonardo Tondo, La Repubblica, 28-III-2004. El autor es docente de psicología en la Università di Agliari y Lecturer en la Harvard Medical School de Boston, en Italia è stato tra i primi a sottolineare i rischi dell'instruzione impartita nelle classi miste. 
entre ambos sexos en ayudarse, interactuar, reaccionar ante los hechos ${ }^{130}$. Y si no se cuidan las adaptaciones, la persona no se conoce, no hay un yo autoconsciente. Tal categoría psicosocial está relacionada con el autoconcepto. La autovaloración específica de cada sexo determina la orientación de los contenidos del aprendizaje y la caracterización de preferencias en actividades y formas de comportamiento ${ }^{131}$. La ausencia de varones proporciona un perfeccionamiento más efectivo y con más camaradería (Hayden, 2005).

Esto se explica al concretar un tanto más el proceso de enseñanza-aprendizaje que sigue cada sexo. A ellas, la escuela les resulta más conveniente, siguen un proceso de identificación cara a cara como con su madre (positividad). Además, prestan más atención, observación, adaptación, siguen la moda. Los chicos, en cambio, además de presentar actitudes de inaccesibilidad, se oponen a su padre (negatividad); mas, para proseguir en la escuela, han de identificarse con el profesor, aunque, de hecho, sucede al contrario. De esto sacamos un conjunto de factores que llevan a desinteresarse por las tareas de clase. No obstante, los hijos de maestros suelen imitar al padre y llegan a formarse profesionalmente acabando en la Normal Superior. Por consiguiente, el sexo llamado «fuerte», en realidad psíquicamente es débil, en pedopsiquiatría, dos tercios de los atendidos presentan problemas de adaptación escolar, pues tienen problemas de separación de las madres, proyectando actos agresivos. Esto aclara que tengamos tantos problemas de disocialización ${ }^{132}$.

${ }^{130}$ Sarah Hayden, manager of Boulder's Outdoor Divas shop, said: «It's definitely a different dynamic. When it's all girls, the group works together so differently in how they take feedback, how they give support and how they interact». The combination of female camaraderie and the absence of men makes the training effective, en: [http:/ / www.denverpost.com/], 8-III-2005.

${ }^{131}$ Barrio, op. cit., p. 53-54.

${ }^{132}$ «[Ellas] D’emblée, l'école leur convient mieux. Les filles sont dans un processus d'identification visà-vis de leur mère alors que les garçons s'opposent à leur père. Pour réussir à l'école, il faut s'identifier aux professeurs. Ce n'est d'ailleurs pas un hasard si les enfants d'enseignants se retrouvent très majoritaires dans certaines écoles telles que Normale sup. Les filles ont des capacités d'observation et d'adaptation très grandes, de déguisement — elles suivent la mode— les garçons sont plus dans un rêve inaccessible. Le sexe dit "fort" est en réalité psychiquement faible. En pédopsychiatrie, deux consultations sur trois concernent des garcons, ils sont plus souvent touchés par l'instabilité, le retard de langage et les problèmes d'adaptation à l'école. Ils rencontrent plus de difficultés à se séparer de leur mère et manifestent des problèmes d'agressivité. Les signes de "dyssocialité" sont encore l'apanage des garçons. Or l'école prépare à la société... Mais au bout du compte, les garçons s'en sortent mieux que les filles notamment parce que ces dernières n'investissent pas de la même façon les meilleures filières et se laissent rattraper par un rôle social traditionnel...». Marcel Rufo, Tout ce que vous ne devriez jamais savoir sur la sexualité de vos enfants. 
La panorámica escolar nos muestra que los chicos llevan la voz cantante en la vida académica, en perjuicio de las chicas. A ellos sólo les interesa ser los dueños de la situación. Y no es que en la clase no los comprendan; la prueba está que, en los centros mixtos, los muchachos entienden bien a las chicas, pero les pierden el respeto ${ }^{133}$. La materialización de estas actitudes se muestra en que los chicos dominan el clima de los procesos de aprendizaje en las clases mixtas, y las muchachas se ven obligadas a adaptarse a los estándares masculinos mediante el aprendizaje social. También, a la hora de sentarse, en todos los niveles se verifica la tendencia de buscar la cercanía por el género, sobre todo en los ejercicios grupales. En los debates, cuando una alumna expone argumentos a favor de una tesis, suele ser respaldada por las de su mismo sexo, y viceversa ${ }^{134}$. Esto contradice lo expuesto en las tesis a), b), d) y g).

Se constata en educación infantil, que las educadoras se inclinan más por las niñas, de modo consciente o inconsciente las prefieren y aducen que juegan con más cordura, son menos ruidosas y atienden con mayor docilidad. El empeño por el que los chicos pretenden instintivamente liberarse de la tutela femenina, puede extenderse desde la edad de la obstinación hasta la educación secundaria. Muchos chiquillos pretenden fortalecer su prestigio para afirmar su autoestima mediante el activismo y llamando la atención. Ante un agravio, el estar continuamente y casi de manera exclusiva rodeados de personas femeninas, les provoca un blindaje progresivo de sus sentimientos: ocultan preocupaciones, se reprimen, desmienten hechos, etcétera. Durante la enseñanza primaria, desde los 6 a los 12 años, si los hechos continúan así, experimentan la sensación de verse postergados. Tales sentimientos son reforzados al obligarles a permanecer sentados durante muchas horas por día. La acumulación de ese estado emocional desencadena alborotos. Se menciona que hasta un 90 por ciento esa salida ante la frustración marca las diferencias entre los sexos. Pero, aún más, si la formación se fundamenta en el diálogo, entonces la educación diferenciada, al ofrecer docentes del mismo sexo,

\footnotetext{
${ }^{133}$ D.K. Hollinger y R. Adamson, Single-sex schooling: proponents speak, (ed. 1991), p. 11 y ss.

${ }^{134}$ Von Martial, en Barrio, p. 57-59.
} 
personalizar la orientación y efectuar la tutoría, permite que la conversación sea a la vez más natural y profunda ${ }^{135}$.

Como proceso de formación de la personalidad, si se pretendía que la mezcla sexual redujera las diferencias, en lugar de ocasionar una desviación de los dominios específicamente masculinos, constata von Martial que sucede al contrario. La educación diferenciada promueve una forma más reafirmativamente independiente del sexo que el modelo coeducacional. La razón se halla en el constructo «aprendizaje social»: como éste está vinculado a las atribuciones específicas de cada sexo, se comprueba que la enseñanza mixta fomenta la polarización de los caracteres sexuales en vez de equipararlos, pues cada grupo de género desea distinguirse más subrayando lo específico. Por esto apreciamos más interés grupal por ciertas asignaturas y actividades circumescolares (Stanworth, 1986). Por estas razones, el contenido de las tesis b), e) y g) han de ponerse en interrogación.

Si en un aula no hay alumnos de otro sexo, ya no es posible interpretar en clave de género el escaso rendimiento, ni la aversión hacia determinadas materias. Tampoco será posible repartir las tareas en función de ciertos intereses sexuados, comprobándose que éstas se asumen con normalidad (Vermehren, 1980 y 1986).

En cuanto al proceso docente-alumnos, en las aulas mixtas hay cierta contaminación del clima relacional. Esto se debe a que los comportamientos específicos de los alumnos arrancan unas consecuentes conductas del profesor; actúa éste como efectuando un etiquetado generalizado. Esto puede ocurrir si el enseñante interpreta en clave de género la disparidad de intereses y rendimientos. Así, las diferencias no serán atribuidas a sujetos sino a individuos que configuran un grupo sexuado. Pensemos en el grado de exigencia para ellas, para aprobar una materia, mientras que los alumnos suelen estar más motivados y ser más eficaces ${ }^{136}$.

${ }^{135}$ F.L. Geis; M.B. Boston y núm. Hoffman, «Sex of authoriry role models and achievement by men and women: leadership performance and recognition», Journal of Personality and Social Psychology, p. 636 y ss.

${ }^{136}$ Stanworth, 1986, p. 25 y ss., citado por von Martial, en Barrio, p. 64-65. 
III.4. Desde una perspectiva empírica y holista, veamos algunas experiencias. Las prácticas escolares en Australia, Canadá, España, Gran Bretaña, Japón, Suecia y EUA, entre otros países, cuestionan cada vez más la educatividad del modelo coeducativo ${ }^{137}$. Pero es significativa una escuela católica, cuyos estudiantes no alcanzaban un nivel mínimo y tenían problemas de indisciplina, que ha adoptado el sistema de separación de sexos. El cambio resultó positivo para preparar a los alumnos para la high school ${ }^{138}$. Hemphill Elementary School constataron buenos resultados en educación separada de sexos con respecto a la coeducación ${ }^{139}$. En el mismo sentido transcurre la educación secundaria en el Huffman Middle ${ }^{140}$. Lo que constatan es que las alumnas resultan más beneficiadas que los estudiantes ${ }^{141}$. Un estudio empírico sobre una muestra de más de 1,800 estudiantes de

\footnotetext{
${ }^{137}$ Cfr., en: [http:/ / www.singlesexchols.org].

${ }^{138}$ «Schools in Kentucky and Idaho abandoned single-sex classrooms after only one year because neither grades nor test scores improved. Discipline referrals for boys skyrocketed at one school... Sacred Heart School officials said they will track students' progress next school year and believe the change will set it apart from other Catholic schools. The change will also better prepare students for high school», Ripley said; about 75 percent of Sacred Heart students go on to a single-sex Catholic high school. Tracy Jan, The Boston Globe News, 9-IV-2005.

${ }^{139}$ Gigi Douban, The Birmingham News, 29-X-2004: Hemphill Elementary officials put singlesex classes to the test when they found third-grade boys lagging academically and socially. Their test scores were low, and many weren't showing up at school. The girls, on the other hand, had been faring much better. To try to bridge the gender gap, the school initiated its own research project, separating third-grade boys from girls. It collected data and tracked the pupils' progress. The results were that girls flourished in class without boys, but boys didn't improve enough to keep their single-sex classes going for another year. Principal Gwen Tilghman said. «We felt like the boys might benefit from being in a mixed setting».

${ }^{140}$ Boys and girls in sixth, seventh and eighth grades are taking classes separately this year at Huffman Middle. Officials there are collecting data, and if results are good, single-sex classes will continue, Principal Marilyn Gibson said. «The teachers really like it». Cfr. The Birmingham News, 29-X-2004.

${ }^{141}$ «Ma se le femmine sembrano favorite dalle classi separate soprattutto sotto il profilo dei comportamenti, dal punto di vista strettamente scolastico i più danneggiati dall'educazione mista appaiono i maschi. Che sviluppano più tardi e più lentamente in settori come le abilità linguistiche, che invece sono privilegiate dalla scuola, apprendono più facilmente se lo stile di insegnamento è dinamico anziché libresco, e risentono dell'onnipresenza femminile nel corpo insegnante, che nega loro modelli dello stesso sesso con cui identificarsi. Nel confronto con le coetanee più diligenti e mature non reggono il ritmo, per cui diventano disattenti e svogliati, e spesso restano indietro. Non è un caso, dicono gli esperti, se nelle scuole superiori gran parte della dispersione scolastica riguarda i ragazzi», La Repubblica, 28-III-2004.
} 
secundaria, pertenecientes a 75 centros, asegura que los alumnos de la diferenciada rinden más y tienen mayores aspiraciones ${ }^{142}$.

Por otra parte, estudiando comparativamente los rendimientos de ellos y ellas en clase de octavo de instituto, en la Realschulle (bachillerato técnico) y Volksschule (primaria), se constata que los resultados de lectura $\mathrm{y}$ vocabulario son mejores en régimen mixto que en separado, tanto para los chicos como para las muchachas. En cálculo, siguiendo la diferenciación, era mejor para los alumnos, pero en mixta es mejor para ellas (Demant, 1955). Von Martial (Barrio, 2005), tras considerar diversas investigaciones y datos plasmados en tablas, menciona el informe de Smith (1980) según el cual, considerando diversos factores — docentes, alumnos, situaciones-, se asegura que el contraste crítico de todos los elementos, manifiesta que la separación de sexos había de considerarse como una variable decisiva.

Sin embargo, ¿la escuela diferenciada es una balsa de aceite, no hay ningún tipo de problemas? En Australia, cuando el profesor Wendy Martín entró temprano a su aula no coeducacional del Appin Park Primary School había un ambiente ruidoso. Se trata de un centro que tuvo problemas serios de indisciplina y ciertas violencias. Por entonces experimentaba las enseñanzas con grupos homogéneos de un solo sexo con la pretensión de prevenir los problemas que antes sucedían; es larga la experiencia mixta en esta institución privada, pero el desequilibrio convivencial favoreció el cambio de modelo. Actualmente, la homogeneización de alumnos según el género y su vuelta a la disciplina ha provocado que la innovación diferenciada se extienda a otras escuelas estatales ${ }^{143}$.

${ }^{142}$ V.A. Lee \& A.S. Bryk, «Effects of single-sex secondary schools on students achievement and attitudes», Journal of Educational Psychology, p. 381 y ss.

${ }^{143}$ When teacher Wendy Martin entered her classroom at Appin Park Primary School earlier this year, the thing that struck her was the noise. «Early on, it was just unenarable. [...] Appin Park is one of a handful of state primary schools experimenting with boys-only classes in a bid to tackle some entrenched problems in boys' education. State secondary schools have long experienced boys-only classes, often to deal with gender imbalances, and the split sex classes are also used in some co-ed private schools. But in state primaries, the concept is a radical one». Shane Green, The Age, Melbourne, (Australia), Education Editor, 11-X-2004. 
Además, Véronique Gass, vice-presidente de l'UNAPEL ${ }^{144}$, ha manifestado la existencia de violencia sexista, subrayando las graves dificultades que surgen entre chicos y chicas en ciertos colegios. Hay un desnivel en la madurez sexual o psicoafectiva, por lo que la federación, por razones pedagógicas, estudia instaurar la separación de los alumnos por sexos en ciertos momentos de la jornada escolar ${ }^{145}$.

En esta línea prevé organizar las enseñanzas la Sacred Heart School -Roslindale, Estados Unidos-, siendo que fue la primera que implantó la coeducación. Esto lo hace a la par con la administración educativa. La razón está en la creencia de que la separación de sexos potenciará el nivel de enseñanza y la autoconfianza, así como el que los chicos no interrumpirán las clases para impresionar a las muchachas, y éstas no se sentirán tímidas o asustadizas ante sus insinuaciones ${ }^{146}$.

En abril de 2000, el US Department of Education publicó un informe sobre el tema. Concluye en que la superioridad global de las niñas en las escuelas es objetiva y constante. Esto se especifica más en lenguaje; si hay más chicos en deportes, ellas ocupan más puestos en todo lo demás (delegadas, redactoras del periódico, etcétera); alrededor de los diecisiete años, las posibilidades de recuperar las tareas escolares en casa es cuatro veces más en los chicos que en ellas; las féminas sistematizan mejor y planean las actividades de aprendizaje, integrando las enseñanzas ${ }^{147}$.

${ }^{144}$ Federación de padres en defensa de la enseñanza privada.

${ }^{145}$ "L'UNAPEL a noté l'existence de "violences sexistes" en soulignant les "grosses difficultés" qui se posent dans certains collèges entre garçons et filles, avec "un décalage de maturité sexuelle ou psycho-affective". L'UNAPEL étudie la possibilité d'instaurer des moments où garçons et filles pourraient temporairement être séparés "pour des raisons pédagogiques"», AFP, 10-II-04.

${ }^{146}$ Sacred Heart School in Roslindale will become what appears to be the state's first coed school, public or private, to separate the sexes in academic classes, according to education specialists and a state Education Department official. School administrators, who told parents of the change this week, said they hope the separation will boost students' grades and self-confidence. Boys will no longer disrupt class to impress girls, they said. And girls won't be shy about speaking out. Tracy Jan, The Boston Globe News, 9-IV-2005.

${ }^{147}$ «In the current school year, 154 public U.S. schools are offering same-sex education, compared with just four public schools eight years ago...». The experiments are part of the biggest change in coeducational public education since Title IX passed in 1972 and barred sex discrimination in federally funded programs. Working in teams to sort words by patterns, the boys look more like they are in a noisy clubhouse than a classroom. Here and there are comfy beanbag chairs for reading, and signs dangle overhead for the Cobra Tribe, Panda Tribe and Great White Wa Wa Tribe. «I think the all-boys classes are really cool», said Colt Campbell, 10, a student in Natalie Wirtz's fifth-grade class. The Washington Post, 8-I-2005. 
En 2001, el Australian Council for Educational Research publicó un estudio empírico, sobre una población de 270.000 alumnos con relación a unas 53 asignaturas. Los que estaban en clases diferenciadas por sexos superaban a los del modelo mixto entre un 15 y 22 por 100, en función de qué materia se tratase. El contexto social y familiar de procedencia se contempló para aceptar tales resultados. Es más: los sujetos de cada sexo de los centros con enseñanzas diferenciadas, tendían a comportarse mejor, disfrutar del centro y valorar más sus resultados académicos ${ }^{148}$. Summers realizó estudios empíricos transversales y experimentales. Los datos tomados de colegios mixtos manifestaban que las chicas no estaban capacitadas para ciencias y técnicas; pero, los ofrecidos a partir de centros diferenciados, resultaban claramente contrarios a la anterior tesis ${ }^{149}$.

El Finantial Times recoge cada mes de agosto los resultados de las top independent schools desde hace años; de las 25 escuelas que obtienen los mejores resultados, más de la mitad son de chicas y el resto de chicos: la primera mixta aparece en el número 26 de la lista. También, en Irlanda, se efectuó un estudio transversal con unas 2,300 estudiantes, señalando mayor capacidad cognoscitiva, autoconocimiento y autocontrol en las chicas de los centros diferenciados ${ }^{150}$.

${ }^{148}$ Christina Sommers, publicada en el libro editado por Barrio, 2005, p. 245-246. En este orden de cosas, esto se concreta en un centro. [Según] La Appin Park Primary School de Australia: «The move coincides with the sense of crisis surrounding the performance of boys compared with girls, showing up in lower literacy and numeracy levels, and lower retention rates. The idea of the boysonly class grew from concern about a group of boys who were losing interest in school. They didn't want to attend school, and weren't happy being there. Ms Martin said some of the boys were suffering low self-esteem. It is here that the boys' social skills really developed. "That's where the encouragement and support they show for each other has really blossomed" (=realizado)», Martin said. Shane Green, The Age, Melbourne, (Australia), Education Editor, 11-X-2004.

${ }^{149}$ Sylvester Brown Jr. Of the St. Louis Post-Dispatch, 20-I-2005. Summers created a stir at an academic conference last week. Factors other than discrimination need exploring, Summers said. Married women with children aren't top university faculty members because they are reluctant to commit the extraordinary amounts of time necessary to excel. But Summers suggested that gender might be another reason why boys tend to outperform girls in science and math. Several outraged female academics stormed out during the presentation. In a New York Times article Tuesday, Summers apologized for any misunderstandings, but he insisted it's necessary to discuss the «multiple factors». [...] «Girls and boys have been stereotyped. We educators have to focus on getting beyond the stereotypes». E-mail: [sylvesterbrown@postdispatch.com]. Tel.: 314-340-8374. Talk in his forum: [http:/ / www.stltoday.com/forums/].

${ }^{150}$ E. Cairns, «The relationschip between adolescent perceived self-competence and attendance at single-sex secondary school», British Journal of Educational Psychology, p. 207 y ss. 
El francés Fize declaró que su principal objeción a la coeducación es que se toma como un dogma que se impone rígidamente, sin importar sus desventajas ${ }^{151}$. Este sociólogo no ve muchos problemas en los colegios mixtos cuando los niños son más pequeños, la dificultad se presenta una vez que alcanzan la adolescencia, pues en esta etapa muchas chicas se sienten vulnerables cuando tienen que estudiar codo con codo con chicos.

La clave es ética, es decir, el valor que se otorgue al sexo en el proceso de desarrollo de la vida humana. Si lo trivializan, sin importar un bledo, entonces no se preocuparán de las diferencias sexuales en la vida ni, en consecuencia, en la educación. Por el contrario, si es importante considerar el sexo como una de las facetas importantes de la personalidad, entonces la sexualización de las enseñanzas ha de tomar posición. Este último sentido nos dice que si las personas están para relacionarse positivamente unas con otras, esto exige una educación que los integre en su identidad sexual. Éste es uno de los principales frutos de la educación diferenciada.

III.5. El problema de la identidad en relación con la coeducación se plantea principalmente en la pubertad y en la adolescencia. En estas etapas de la personalidad se consolidan los caracteres sexuales, así como pueden tomar forma ciertas aberraciones, vicios o debilidades al respecto. Así que, educativamente, si hay diferencias sexuales evidentes en la personalidad, se exige una educación diferenciada. ¿Tienen importancia las predisposiciones en el origen de las diferencias de género?, ¿se trata de mayor influjo ambiental? Esta cuestión está considerada por von Martial ${ }^{152}$, que recoge diversos estudios. Concluye afirmando que existe base suficiente para afirmar que las diferencias de sexo descansan en parte sobre disposiciones específicas de cada uno, que ser chico o chica no es un factor determinante para la evolución del rendimiento en una asignatura; pero las aptitudes son relevantes en ello.

Hay que profundizar un tanto más sobre las claves, el porqué de las diferencias. Tal vez no se contemplaran bien las raíces del problema. Hay

${ }^{151}$ Entrevista en La Vanguardia, 15-IX-2004.

${ }^{152}$ Barrio, op. cit., p. 49 y ss. 
que considerar los modelos desde la matriz antropológica. Tales fundamentos se relacionan con la identidad sexual, aspecto que hasta ahora no tenía avances tan claros en el estudio del genoma humano. Las hipótesis de partida en contra de la educación diferenciada se hallan en afirmaciones como que las diferencias de género serían más un resultado del influjo social que de disposiciones heredadas (Greenglass, 1995). No se trata de negar la influencia del medio en el desarrollo y consolidación de las aptitudes, pero sí de señalar que existen factores determinantes de la sexualidad humana. Von Martial menciona argumentos refutadores desde lo lingüístico, espacial, comportamiento, juicio moral, etcétera ${ }^{153}$. ¿A qué causas se debe esta diferenciación?, ¿es fundamental? Si así fuera, la antropología de los géneros fundamentaría la separación de los sexos en las escuelas (Schellenberg, 1995). En tal modelo se parte de predisposiciones físico-psíquicas para aplicarse a unas u otras materias. No obstante, hay que concretar aquí el basamento de las mismas.

Hace 300 millones de años aparecieron los cromosomas sexuales $\mathrm{X}$ e $\mathrm{Y}$. Sólo 54 genes, de los 1,100 genes hallados en el cromosoma $X$, tienen un homólogo funcional en el cromosoma Y. El primer mapa elaborado del cromosoma sexual $X$ volvió a sembrar un gran enigma en la biología: ¿por qué las mujeres necesitan más genes que los varones para vivir? Tal es la interrogante que surge de la decodificación casi completa (99,3\%) del cromosoma $X$, otro paso clave para la ciencia, presentado en la portada de la revista Nature. Como el género femenino tiene dos copias del cromosoma $X$, se pensaba que una de éstas estaba apagada para evitar una duplicación genética. Sin embargo, el estudio constató que ese cromosoma dormido está bien despierto: mantiene activo el 15\% o más de sus genes, lo que proporciona a las mujeres genes sexuales extras.

La concreción de tales diferencias en lo fisiológico y funcional, lleva a verificar la superioridad de las muchachas mediante la dotación de la función de coordinación lingüística de la región de Werlicke, que en los varones es un 30 por ciento más reducida. En consecuencia, a menor capacidad en lenguaje, menos discurso con códigos y menor posibilidad en la 
integración de conocimientos. Esto significa un prejuicio en contra de los varones con relación a la productividad. La aptitud para la reflexión que impulsa la mejor aplicación para las ciencias técnico-prácticas -aparte de que existe un núcleo nervioso bajo el hipotálamo dos veces mayor en el chico que en las chicas-, se consolida en la pubertad; tal predisposición aumenta con la influencia de la hormona sexual masculina. Luego, desde la pubertad (12-14 años) y adolescencia, las aptitudes se socializan. Entonces las distancias en rendimiento tienden a equiparase, porque ellas se centran en interesar al varón y ellos en intentar la promoción social mediante el estudio. Mas, hasta entonces, hay muchos excluidos por el camino ${ }^{154}$.

El Instituto de Medicina de Estados Unidos ${ }^{155}$ aseguró, en un informe preparado por un panel de 16 expertos, que las diferencias intersexuales pueden advertirse en el número y la gravedad de una amplia gama de enfermedades, y que muchas funciones fisiológicas normales -y en muchos casos, funciones patológicas - se ven influidas directa o indirectamente por las diferencias biológicas, según menciona el informe. Mary Lou Pardue, científico del Instituto de Tecnología de Massachusetts (MIT), afirmó en el prólogo del informe que el sexo masculino o femenino "sí importa». "Tiene una relevancia que no esperábamos. Sin duda, importan formas que ni siquiera hemos comenzado a imaginar» ${ }^{156}$.

Por consiguiente, las diferencias entre varón y mujer comienzan en el cerebro. Esto va desde la diferencia sexual a la anatómica y funcional, ocasionadas por la intervención de las hormonas que actúan ya prenatalmente en la virilización o feminización del cerebro. Por tanto, la maduración de la capacidad cognitiva viene en un modo y tiempo diverso pero

\footnotetext{
${ }^{154}$ Esto es un resumen del capítulo de Christina Meves: «Las chicas son diferentes, los chicos más», traducido por J. M. Barrio Maestre y publicado por este, op. cit., p. 249 y ss.

${ }^{155}$ Es organismo científico independiente que asesora al gobierno de E.U.

${ }^{156}$ Fuente: [http:// soloellas.com/].
} 
particularmente en la pubertad. Tales diferencias comienzan ya durante el embarazo, en donde mueren muchos más fetos masculinos que femeninos ${ }^{157}$.

Los estrógenos y la testosterona concretan la identidad. En consecuencia, varones y mujeres piensan, sienten, perciben, reaccionan, responden, aman, necesitan y valoran de manera casi totalmente diferente ${ }^{158}$. En este sentido, el inglés Michael Gurian ha identificado más de cien diferencias entre varones y mujeres ${ }^{159}$, lo cual ha sido un factor para justificar la separación de sexos en educación y decantarse en pro de la educación diferenciada de los sexos, aduciendo que la mezcla de géneros en las aulas ocasiona prácticas sexistas discriminatorias ${ }^{160}$.

${ }_{157}$ «Invece, è una proposta sostenuta da persone di ogni colorazione ideologica (la difende, ad esempio, Hillary Clinton), e che si basa su uno tra i risultati più importanti dei recenti progressi delle neuroscienze: le differenze tra uomini e donne cominciano anzitutto dal cervello. A dirlo è ormai una montagna di dati scientifici, che sottolineano differenziazioni sessuali sia a livello di strutture anatomiche sia di funzionamento. E poi ché questa diversità sembra determinata in gran parte dagli ormoni, che intervengono già in età prenatale a "virilizzare" o "femminilizzare" il cervello, non stupisce che anche la maturazione delle capacità cognitive avvenga in modi e in tempi diversi, e che questo risulti particolarmente evidente negli anni della pubertà». «Intellectual tsunami is one description for what's happened in the days since Summers' remarks became public. The left protested vociferously. The right defended him, citing tidbits of research. Thus conservative columnist Linda Chavez placed great weight on a Johns Hopkins study that showed that among gifted pre-adolescent children, boys outperformed girls in math 13 to 1 . In an effort to stem the waves of anger, Summers apologized in person to a group of women professors Thursday. In fact, the evidence does not support the idea that innate differences are at fault. Among adults, cognitive sex differences in how adult women and men think have turned out to be much smaller than previously believed. According to recent studies, there's a lot of variation within each sex and lots of overlap between the sexes. The most important breakthrough has been the discovery that the various regions of the brain develop in a different sequence in girls. Researchers at Virginia Tech used sophisticated electrophysiologic imaging to examine brain development in 508 normal children -224 girls and 284 boys - ranging from 2 months to 16 years. These researchers found that while the areas of the brain involved in language and fine motor skills (such as handwriting) mature about six years earlier in girls, the areas involved in math and geometry mature about four years earlier in boys. The real problem is not with the different mental capacities of boys and girls but with the way they are taught». Summers, La Repubblica, 28-III-2004.

${ }^{158} \mathrm{~J}$. Gray, Los hombres son de Marte, las mujeres de Venus.

${ }^{159}$ M. Guriam, Boys and Girls Learn Differently, 2001.

${ }^{160}$ «We're at the point where we've identified more than 100 differences between the male and female brain», said Michael Gurian, a Spokane, Wash., writer whose book Boys and Girls Learn Differently was instrumental in Frederick County's decision to try same-sex education. He rejects the idea that segregating students by gender and styling their classes differently is a return to sexist practices. «We're not talking about putting them up on a mountaintop for 12 years», he said. The Washington Post, 8-I-2005. 
Existen dos actitudes muy diferentes en las aulas. Los chicos tienden a la conquista del poder; las chicas tienden más a la imaginación y a lo romántico, que su condiscípulo no es el príncipe azul, etcétera ${ }^{161}$. La concreción de esto en lo sociocultural es la siguiente: lo que más motiva a un varón es vencer; a una mujer, aprender. Ellos desean: ganar partidos, apuestas, batallas, dinero, conquistas... Ellas anhelan: aprender de lo desconocido, descubrir, atreverse, sumergirse, experimentar. Puede que ellos necesiten un fin y ellas un por qué. $\mathrm{O}$ al menos eso respondería al espectacular aumento de usuarias de servicios culturales, avalado por todas las encuestas, frente al estancamiento de los varones en ese terreno.

Hoy, lo anterior puede concretarse estadísticamente. En el registro del IDESCAT (Institut d'Estadística de Catalunya), con datos de 2001, figuran las listas de actividades culturales en las que se detecta más presencia femenina: lectura (1.679.000 mujeres; frente a 1.503 .000 varones), práctica de la escritura (382.000 mujeres; 308.000 hombres), asistencia a bibliotecas (925.000 mujeres; 912.000 varones), teatro (820.000 mujeres y sólo 733.000 varones), danza (224.000 mujeres; 171.000 varones)...

Su tiempo libre también lo dedican a cosas distintas. Unas 682.000 mujeres catalanas escogen leer, frente a 587.000 varones. Ellos se decantan por ir al gimnasio o practicar algún deporte. Mireia Bofill, coordinadora del Centre de Cultura de Dones "Francesca Bonnemaison», expone que las mujeres siempre han sido, a la vez, creadoras y transmisoras de cultura, aunque interesara ocultarlo. Es en ese sentido como los sociólogos han dibujado la diferencia entre la ambición masculina y la femenina. Mientras la primera tiende a ser vertical (cómo subir, cómo triunfar, cómo ascender), la femenina sería una ambición horizontal (cómo aprender más, cómo ampliar disciplinas, cómo investigar nuevos caminos).

${ }^{161}$ «Les filles partent à la recherche du prince charmant et font croire à ceux qu'elles rencontrent qu'ils remplissent cet idéal. Pris au jeu, les garçons, eux, partent à la conquête du pouvoir. Et si finalement elles se rendent compte que leur compagnon n'est pas tout à fait le prince charmant, elles reportent les mêmes idéaux sur leurs enfants imaginant leur fille en Sissi impératrice et leur garçon en Zidane ou Armstrong à la conquête de l'espace». Marcel Rufo, Tout ce que vous ne devriez jamais savoir sur la sexualité de vos enfants. 
Sommers ${ }^{162}$ es una defensora de la educación diferenciada por sexos, y basa sus argumentos en que «décadas de investigación en neurociencia, endocrinología, genética y psicología, sugieren que existen diferencias entre sexos en las aptitudes y preferencias, que son innatas y no creadas por la sociedad. Entre las diferencias biológicas que influyen en la educación está el hecho de que los chicos cuentan con mejores capacidades de razonamiento espacial, mientras que las chicas tienen más capacidad verbal; el género masculino es más propenso a correr riesgos, y el femenino es más maduro; los chicos prefieren la acción, la competencia y los objetos inanimados, y constituyen un grupo que no emplea demasiado tiempo en hablar de sus propios sentimientos. Esto implica predisposiciones negativas que no facilitan la tutoría educativa. Por otra parte, como los chicos se dejan seducir por fantasías agresivas, esta predisposición facilita situaciones de indisciplina escolar».

En cuanto a la vivencia de los valores, las especificaciones que caracterizan al niño y a la niña (las diferencias de sexo) — qué duda cabeconstituyen un hecho psicológico, con independencia de cuál sea el pensamiento dominante de la época. Durante la edad escolar los chicos se manifiestan más impulsivos, menos ordenados y con mayores dificultades para concentrarse en los estudios y/o manifestar sus emociones. Por el contrario, las chicas a esas edades están mejor capacitadas para vivir el orden, la puntualidad y la constancia en el trabajo, y lo que es muy importante: expresan con facilidad sus emociones. Es muy diversa también la naturaleza de la afectividad en unas y en otros. En ellas, la delicadeza, la atención en los detalles y el énfasis que otorgan a lo emotivo, fundamentarán más tarde su afectividad femenina. En los chicos, en cambio, su vida afectiva está caracterizada por los rasgos de dureza, insensibilidad y rudeza, descalificando globalmente la vida afectiva, que es percibida en esta etapa evolutiva como desprestigiada y hasta banalizada.

${ }^{162}$ Cristina Hoff Sommers es una vieja conocida de los lectores y espectadores estadounidenses. Cfr. su trabajo The war agains boys: how feminism is harming our young men. Muchos de los programas de prime time en aquel país han acogido sus comentarios en debates sobre el feminismo - la cuestión por la que más se le conoce-, los malos tratos o las dificultades por las que pasan los chicos en las escuelas mixtas de Estados Unidos. Expansión, Madrid, 28-IV2004. 
De lo expresado no debe concluirse que en el mundo afectivo del varón no haya lugar más que para la violencia. No es eso. En su ámbito afectivo existe también un espacioso lugar para la ternura, sólo que está encerrada y no hace nada por manifestarse. Más tarde, durante la etapa adulta, aparecerá la ternura masculina, aunque expresándose de modo muy diverso a como acontece a las chicas. En ellas sucede lo contrario: aparece primero la ternura femenina que, más tarde, tal vez se mude en violencia de forma verbal ${ }^{163}$.

\section{CONSECUENCIAS PEDAGÓGICAS}

Las diferencias biológicas, por tanto, han de fundamentar una forma de educación distinta a cada sexo. Así mismo, conviene que los niños se encuentren un ambiente estructurado y que se haga énfasis en cómo se han de organizar; que se apliquen sanciones si no se realiza el trabajo requerido; menos ficción y más libros sobre cuestiones y cosas concretas; clases divididas en grupos donde haya cierta competencia... Las chicas no necesitan un control tan estricto. Trabajan bien en pequeños grupos, en clases tranquilas y creativas. Conviene interesarlas pronto en actividades deportivas de equipo, y necesitan más atención en materias como las matemáticas o las ciencias. Las chicas tienden a minusvalorar sus habilidades, y necesitan aliento constante (al contrario que los chicos, que suelen sobreestimar sus capacidades, incluso cuando no las tienen).

En lo concerniente a los temas típicos de educación sexual, la diferenciada es mejor para las chicas, pero las investigaciones pueden estar influidas, por lo que no se pueden generalizar; así, no encontramos condiciones para incrementar la implicación de chicos en estereotipos disciplinarios respecto a las niñas. Así mismo, se ha encontrado que las adultas educadas en escuelas separadas ofrecen actitudes menos estereotipadas con relación al sexo, así como un autoconcepto más elevado ${ }^{164}$. Por esto el balance está a favor de la separación de los alumnos en las enseñanzas.

\footnotetext{
${ }^{163}$ Marga Monforte, El Tiempo.

${ }^{164}$ V.E. Lee \& A.S. Bryk, «Effects of single-sex secondary school on student achievement on attitudes», Journal of Educational Psychology, p. 381 y ss.
} 
Esta tesis ya es defendida por personalidades de diverso color político. Investigaciones oficiales de Suecia ${ }^{165}$ nos aseguran que el fracaso de la educación actual se debe al empeño por despreciar las diferencias entre los sexos. Por tales razones, investigadores sobre el asunto señalan que la creencia de que los niños necesitan de colegios mixtos para enseñarles a comunicarse con el sexo opuesto es anticuada. «Nuestras chicas tienen una vida social, hay un montón de todo eso (comunicación, relaciones, etcétera) fuera de los horarios escolares, pero en clase, se concentran en el trabajo académico» ${ }^{166}$.

La traducción escolar de estas premisas es clara: existe una conducta social y un trabajo específico de los sexos (Gehlen, 1988). Lo dicho sobre las inclinaciones por unas $\mathrm{u}$ otras materias curriculares ya es una ejemplificación; también la predisposición a cooperar en aparatos y herramientas o a actividades de voluntariado en lo físico-deportivo.

Socioculturalmente se nos plantea un reto que conlleva unos objetivos y valores a conseguir. El profesor Torns, de la Universidad Autónoma de Barcelona, argumenta en la línea del sociólogo francés Pierre Bourdieu, autor de La dominación masculina, cuando analiza en su ensayo la construcción del gusto en los seres humanos. Bourdieu distinguía tres clases de gustos que corresponden a tres clases sociales: el gusto legítimo (o burgués), el gusto medio y el gusto popular. Sus respectivas producciones son: obras de arte, bienes y mensajes de consumo masivo. "La mujer no llegará a ser verdaderamente libre -anuncia Bourdieu- hasta que pase de ser objeto cultural a gestor de los bienes culturales» ${ }^{167}$. Por consiguiente, lo antedicho no significa que las misiones, funciones y tareas, roles y estatus deban ser fijados estancamente y sean inamovibles, impidiéndose que ellas puedan asumir lo que la tradición había fijado para el varón; ni tampoco de forma viceversa. Pero esto no justifica ofrecer modelos discriminatorios.

Estamos con la postura de Hoff Sommers, que se muestra contraria a la creación de un mundo hostil entre el hombre y la mujer. Él cree en la

${ }^{165}$ Ch. Heister, presidenta de la Comisión para el Estudio de la Educación, julio 2004.

${ }^{166}$ Gill Pyatt, Telegraph (Londres), 11-VII-2004.

${ }^{167}$ Núria Escur, «Ellas prefieren aprender, y ellos actuar», La Vanguardia, 13-IV-2005. 
complementariedad y en la ayuda mutua ${ }^{168}$. Lo que aquí se defiende es un currículo que posibilite el despliegue de las potencialidades específicas de cada sexo ${ }^{169}$. En consecuencia, la separación de chicos y chicas es un modelo más idóneo para lograr tal fin, o - como manifiesta Langecondicionar las enseñanzas mixtas en cuanto que orientadas por mujeres, etcétera, sin perjudicar la igualdad de oportunidades.

Una base para la equidad es que todas las escuelas dispongan de un mismo plan de estudios, pero que en el desarrollo curricular del mismo, un tema pueda ser tratado específicamente según el grupo sexual que esté aprendiendo. Es más, habría que diseñar espacios libres para el desarrollo personal, impedir los contactos sexuales prematuros, implicar la formación moral sexual, etcétera.

\section{CONCLUSIONES Y PROPUESTAS}

En sus investigaciones, Fize descubrió que la educación mixta, por sí misma, no suprime las desigualdades. También puso de relieve que la educación mixta se impuso en Francia por razones de tipo económico, básicamente, al no poder hacer frente a la gran demanda social de educación para los niños y jóvenes. Denuncia que todas estas decisiones se tomaron sin ningún debate ni argumentación pedagógica. En 1982 fue la primera vez que un texto oficial se refirió a la razón de la igualdad de chicas y chicos, pero sin más explicaciones. Fize se queja de que en Francia la coeducación es un «dogma», intocable porque se asocia a «égalité» que para los franceses significa igualdad; la diversidad, por tanto, es mal vista; $\mathrm{y}$ «separar» es entendido como «desigualdad» $\mathrm{y}$ «discriminación» ${ }^{170}$. Se ha

${ }^{168}$ Expansión, Madrid, 28-IV-2004.

${ }^{169}$ Se sigue la propuesta de la feminista Helene Lange, 1928, vol. II, p. 67 y ss., citada por von Martial, vía Barrio, 2005, p. 67.

${ }^{170}$ Michel Fize. Nacido en Levallois en 1951, es sociólogo e investigador del CNRS francés. En los 90 colaboró con Edouard Balladour. Fue consejero en el Ministerio Francés de Juventud y Deportes en 1997 y 1998. Especialista en temas de familia y juventud, ha publicado diversos libros como Adolescence en crise? (Hachette, 1998); A mort la famille! Plaidoyer pour l'enfant (Erès, 2000), y Le deuxiènme home (Presses de la Renaissance, 2001). En 2003 publicó en París la polémica obra Les pièges de la mixité scolaire (Presses de la Renaissance), en la que evidencia las dificultades con que se encuentra la educación mixta. 
comprobado que, en la mayoría de los casos, las justificaciones para promover la coeducación se basan sobre todo en motivos sociales y económicos, siendo escasos los argumentos pedagógicos ${ }^{171}$. No obstante, existen bastantes actitudes y hechos que muestran cambios en la organización escolar francesa respecto a la mixticidad ${ }^{172}$, así mismo en el mundo anglófono ${ }^{173}$. El problema central es que la coeducación no ha tenido en cuenta las diferencias reales entre chicos y chicas; los planes de estudio no se han adaptado, sino que se han dejado como estaban: pensados para los chicos. Aunque las chicas precisan otro ritmo, pueden llegar a entender y asimilar mejor que los chicos aspectos de informática, matemáticas o física. Tal vez por estas razones, Fize defiende que los padres deberían tener la capacidad de escoger si enviar a sus hijos a colegios separados o mixtos.

Resultado de lo anterior, encontramos cierto balance a favor de la educación diferenciada, misma que parece beneficiar más a las mujeres que a los varones, pero ¿es porque se investiga más con ellas que con ellos? En consecuencia, no hay que efectuar afirmaciones tajantes, como se opina por ahí, lo que se afirma sin demostrar, lo políticamente correcto, etcétera. En ocasiones, todo lo que se dice, lo que se lleva... no es lo mejor, ni beneficia necesariamente a las personas, sobre todo si están en momentos de formación, y en edades críticas como la pubertad y adolescencia.

Podemos sintetizar las siguientes recapitulaciones conclusivas:

1. En donde existe educación de un solo sexo, las instalaciones son más sencillas, sobre todo las sanitarias y deportivas.

2. Preparar para la sociedad no implica aprender todo lo que sucede en ésta, pues abundan cada vez más casos corrosivos y aberraciones sociales contrarias a la integridad de la dignidad humana. El clima escolar coeducativo está muy sexualizado e impide procesos serenos de formación.

Marga Monforte, El Tiempo, agosto 2004.

${ }^{172}$ L. Poinsot, «Igualdad de oportunidades entre chicos y chicas en la escuela: ¿las cosas se mueven ya en Francia?», en: [http:/ / www.penelopes.org] .

${ }^{173}$ The two-year study is starting up just as the department has proposed new, relaxed regulations that would allow public schools more leeway to teach boys and girls separately. Vid. Michelle R. Davis, Education week, 24-III-2004. 
¿No sería una opción positiva el mejorar la sociedad mediante la educación, en vez de supeditarnos a lo que sucede (indisciplina, violencia, opresión, engaño...)?

3. En el modelo mixto no se ha conseguido la pretendida igualdad de oportunidades de los sexos, al contrario, los estereotipos se radicalizan; es más, se constatan problemas emocionales y discriminación académica negativa ${ }^{174}$.

4. Al separar los sexos se complementa mejor la vida familiar. Además, en las escuelas suceden tensiones emocionales que en la familia no se presentan, pues los lazos de sangre unen a sus miembros de manera que se minimizan ciertos malentendidos.

5. Por desigualdades en la velocidad y momentos de maduración, las diferencias de rendimiento entre ambos modelos son palpables. El rendimiento académico es más bajo en los centros mixtos que en los diferenciados (Calvo, 2005; von Martial, 2005).

6. Hay aportaciones de bioquímica, fisiología, psicología, genética, etcétera, que manifiestan la existencia de diferencias fundamentales de raíz. Por consiguiente, el sistema escolar no debería tergiversar la naturaleza de los alumnos y escolares.

7. Hay un desequilibrio en el desarrollo psico-somático de ellos comparado con el de ellas. Situados en el proceso formativo y educativo, las muchachas maduran antes y los alumnos se sienten y son apreciados como «menores», con actitudes de cierta discriminación. Igualarles es un contrasentido que coloca barreras al desarrollo personal de cada cual.

8. El conocimiento del sexo opuesto se desvirtúa, pues muchachos y chicas no se proyectan como son, sino como le gustaría a la masa ${ }^{175}$.

\footnotetext{
${ }^{174}$ F.A. Mael, «Singel-sex and coeducational schooling: relationsships to socioemotional and academic development», Review of Educational Reserach, p. 101-129.

${ }^{175}$ M. Calvo, op. cit., p. 271.
} 
9. Las interacciones educacionales resultan más problemáticas en los modelos coeducativos que en la separación de sexos. «La violencia de género es muy elevada» en la enseñanza mixta. La educación diferenciada es una forma de liberar a los varones de una competitividad entre sexos que no beneficia a nadie ${ }^{176}$.

10. Éticamente existen preguntas angustiosas: ¿Cuál es el papel del sexo? ¿Qué sentido posee la propia sexualidad? ¿Libera a la mujer o al varón? El Simposio Man 78 concluye que las muchachas son las perdedoras del modelo coeducacional. Pedagogas feministas critican que la escuela funcione desde un esquema sexista, por lo que las mujeres resultan discriminadas en el modelo coeducacional. Además, las estadísticas señalan que los divorcios y fracasos surgen con mayor frecuencia entre los egresados de centros coeducativos. En tal sentido hay que mencionar los abortos, embarazos precoces y promiscuidad sexual manipulada (Schulz, 1980; Brehmer, 1981 y 1982; Spender, 1985; Enders-Dragäser/Fuchs, 1993; etcétera).

Víctor García-Hoz manifiesta que: «Desde el punto de vista científico no hay evidencia clara para decir que la coeducación sea superior a la educación separada o que ésta sea superior a la primera». Pero lo que no debe imponer la autoridad política es un modelo único de educación que sería signo de un totalitarismo educativo. La elección de un tipo u otro de escuela no es un problema de técnica científica sino de libertad personal y social. Se trata además de una cuestión pedagógica que todavía no ha sido estudiada como debiera, de manera que se conozcan claramente cuáles son los efectos. Aunque desde la perspectiva pedagógica no puede concluirse que la coeducación sea nefasta, tampoco puede considerarse anticuada la enseñanza con separación de sexos. Siempre constituirá un enriquecimiento para la oferta educativa poder contar con las dos opciones. Mi opción preferencial es la educación diferenciada, que no es exactamente la educación tradicional rígida, sino todo lo contrario: aquella que sabe conjugar la educación permanente y esencial con técnicas de vanguardia. 
En suma: al considerar los análisis, las experiencias, las investigaciones y los estudios, podemos afirmar que montar un sistema coeducativo es más simple que la diferenciación de las enseñanzas por sexos. Así mismo, no se ha comprobado que la enseñanza mixta sea mejor que la diferenciada. Por consiguiente, no es deseable que la calidad de la educación esté supeditada a las facilidades administrativas. Ante la suposición de que la coeducación promovería la igualdad radical de varones y mujeres — tachando de artificial la separación educativa de los sexos, aparte de las experiencias que la refutan-, hay que señalar que esa idea podría ser válida para otra época. Ciertamente, a principios del siglo pasado — siglo XX-, la sociedad no era mixta y vivía con alta discriminación contra la mujer y la infancia. Hoy, el sexo ha dejado de ser un tabú, fuera y dentro de la familia. La familia nuclear del siglo XXI ofrece unas acciones educativas altamente superiores a los razonamientos abstractos, instrucción, etcétera, que los temas, asignaturas sobre ciudadanía y demás produce la escuela. La responsabilidad, actitud de servicio, respeto, solidaridad..., es lo que aporta la familia; la mezcla de sexos manifiesta síndromes de indisciplina, enfrentamiento entre varón y mujer, agresión. Así que, en la actualidad, no puede valorarse como obsoleta y rancia la separación de chicas y chicos en el sistema educativo. No obstante, esto no debe implicar una forzosa separación; sería práctica paratotalitaria. Más bien se trataría de posibilitar un modelo pedagógico, en virtud el cual, los padres pudiesen optar.

En conclusión, la opción por la diferenciación, la enseñanza mixta o la coeducación no debe ser una norma, sino una opción. Es similar a la educación religiosa, la lengua materna, etcétera, pues están en el meollo de la dignidad de la persona. En último término, son los padres - y estudiantes, según capacidad y formación- quienes deben asumir la decisión, pero con conocimiento claro del tema. La sociedad (mediante sus órganos, como es el Estado) sólo ha de apoyarles para que puedan hacer lo que decidan, lo que ellos opten. 


\section{BIBLIOGRAFÍA}

- AAVV., How schools shortchange girls, American Association of University Women, Washington, 1992 [on line]:

[http: / / www.aauw.org/research/girls_education/hssg.cfm].

- BARRIO MAESTRE, J.M., Educación diferenciada, una opción razonable, Pamplona, Eunsa, 2005.

- BEAUVOIR, S. de, El segundo sexo (Le Deuxième Sexe), Creatividad feminista, 2004 [en línea]: [creatividadfeminista.org/articulos/2004/fem_chesca_beuvoir.htm].

- CAIRNS, E., «The relationschip between adolescent perceived selfcompetence and attendance at single-sex secondary school», British Journal of Educational Psychology, 60, 1990.

- CALVO, M., Todos iguales pero diferentes. El derecho a una educación diferenciada, en J.M. Barrio (ed.), Eunsa, Pamplona, 2005.

- CONLON, R.W., «Teaching the boys: New research on masculinity and gender strategies for schools», Teachers College Record, 98, 2, 1996, p. 206-235.

- DAVIS, Michelle, R., "Federal Study Examining Single-Sex Public Schools», Education week, 2004 [on line]: [http:/ /www.edweek.org/ ew/articles/2004/03/24/28single.h23.html].

- DUERY, L., El Mercurio, 18-III-2005.

- EDER, D., «The cycle of popularity: interpersonal relations among female adolescents», Sociology of education, 58, 1985, p. 154-165.

- FIZE, M., Les piéges de la mixtité scolaire, Paris, Presses de la Renaisance, 2003.

- FISHER, H., El primer sexo, Universidad de Chile, 2003 [en línea]: [http: / / www.agendapublica.uchile.cl/n5/2_dona.html].

- GARCÍA-HOZ, Servicio de documentación Montealegre, 29, año II, época III, abril, España, 1985.

- GEIS, F.L.; BOSTON, M.B. \& HOFFMAN, N., «Sex of authoriry role models and achievement by men and women: leadership performance and recognition», Journal of Personality and Social Psychology, 49, 1985.

- GRAY, J.M., Los hombres son de Marte, las mujeres de Venus, Grijalbo-Mondadori, Madrid, 2000. 
- HACKETT, G., Suplemento «Education», The Sunday Times, 14-XI2004.

- HOLLINGER, D.K. \& ADAMSON, R., Single-sex schooling: proponents speak, US Department of Education, Washington, 1993.

- HOFF SOMMERS, C., The war agains boys: how feminism is harming our young men, Simon and Schuster, New York, 2000.

- KINDLON, D. y THOMPSON, M., Educando a Caín, Atlántida, Buenos Aires, 2000.

- KLEINFELD, J., «Student performance: males versus females», Public Interest, 3, 20, 1999.

- KRAEMER, S., «The fragile male», British Medical Journal, 321, 23, December, 2000, p. 1609-1612.

- LEE, V.A. \& BRYK, A.S., «Effects of single-sex secondary schools on students achievement and attitudes», Journal of Educational Psychology, 78, 1986.

- LEE, Valerie E.; MARKS, Helen M. \& BYRD, Tina, «Sexism in SingleSex and Coeducational Independent Secondary School Classrooms», Sociology of Education, 67, 2, April, 1994, p. 92-120.

- LODUCHOWKY, H., La coeducación de los adolescentes y el problema de los teenagers, Herder, Barcelona, 1967.

- MAEL, F.A., «Singel-sex and coeducational schooling: relationsships to socioemotional and academic development», Review of Educational Reserach, 68, 1998, 2.

- MONFORTE, M., El Tiempo, Piura, 2000.

- MOSCONI, N., La mixité dans l'enseignement secondaire: un faux semblant? Paris, PUF, 1989.

- ODONE, Ch., «Single-sex schools get top marks», Times Online, 18-XI-2004.

- POINSOT, L. (s/f), «Igualdad de oportunidades entre chicos y chicas en la escuela: ¿las cosas se mueven ya en Francia?» Cfr. en:

[http: / / www.penelopes.org].

- POLLACK, W., Real Boys: Rescuing our sons from the myths of boyhood, Random House, New York, 1998. 
- RIORDAN, C., Girls and boys in school: together or separate?, Teachers College Press, New York, 1990.

- ROJAS MARCOS, L., Nuestra incierta vida normal, Aguilar, Madrid, 2004.

- RUFO, M., Tout ce que vous ne devriez jamais savoir sur la sexualité de vos enfants, Édition Anne Carrière, 2004.

- SAX, L., Why Gender Matters. What Parents and Teachers need to know about the emerging science of sex differences, Doubleday, New York, 2005.

- SMITH, D.G., «Women's colleges and coeducational colleges: is there a difference for women», Journal of Higer Education, 61, 1990, p. 181 y ss.

- TRACY JAN, The Boston Globe News, 9-IV-2005.

- WENDLAND, Joel, «Reversing the Gender gap», Political Affairs Magazine, March, USA, 2004 [on line]: [http: / / politicalaffairs.net/article/view/106/].

- YATES, L., «Gender equity and the boys: What sort of challenge is it?», British Journal of Sociology of Education, 18, 1997, 3. 